\title{
Pharmacologic restoration of the early insulin response in pre-diabetic monkeys controls mealtime glucose excursions without peripheral hyperinsulinaemia
}

\author{
B.E. Dunning ${ }^{1,2}$, R. Deacon ${ }^{2}$, C. Gutierrez ${ }^{2}$, S. Paladini², M.A. Valentin ${ }^{2}$, J.E. Foley ${ }^{2}$ \\ ${ }^{1}$ Novartis Pharmaceuticals Corporation, Ceresco, MI, USA \\ ${ }^{2}$ Metabolic and Cardiovascular Diseases Pharmacology, Novartis Institute for Biomedical Research, East Hanover, New Jersey, USA
}

\begin{abstract}
Aims/hypothesis. This study sought first to compare the pharmacodynamics and pharmocokinetics of two rapid-onset, rapidly-reversible insulinotropic agents, nateglinide and repaglinide, in pre-diabetic Cynomolgus monkeys and second to use these agents to assess the metabolic effects of early insulin secretion on prandial glucose control.

Methods. First, equipotent doses of nateglinide $(20 \mathrm{mg} / \mathrm{kg})$ and repaglinide $(0.1 \mathrm{mg} / \mathrm{kg})$ or vehicle were given intragastrically to overnight-fasted ketamine-anesthetized pre-diabetic Cynomolgus monkeys and samples were obtained for measurement of plasma glucose, insulin, glucagon, NEFA and drug concentrations. Second, nateglinide, repaglinide or vehicle were administered $10 \mathrm{~min}$ before a glucosesupplemented liquid meal and prandial glucose and insulin profiles were compared.

Results. Although oral administration of nateglinide and repaglinide elicited similar maximum increments of plasma insulin (+403 and $+448 \mathrm{pmol} / \mathrm{l}$, respective-
\end{abstract}

ly), the effects of nateglinide were more rapidly manifest and less prolonged. With nateglinide, insulin increased within $10 \mathrm{~min}$ and returned to baseline within $50 \mathrm{~min}$. After repaglinide, the first increase occurred at $30 \mathrm{~min}$ and insulin concentrations remained increased for $3.5 \mathrm{~h}$ post-dose. When given $10 \mathrm{~min}$ before a meal, nateglinide increased early, but not total insulin release $\left(\mathrm{AUC}_{0-210}=108 \mathrm{vs} 150 \mathrm{nmol} / \mathrm{l} \mathrm{min}\right.$ for nateglinide and vehicle, respectively) and reduced prandial glucose excursions by $78 \%$. Repaglinide increased total insulin release $\left(\mathrm{AUC}_{0-210}=298 \mathrm{nmol} / \mathrm{l}\right.$ min) and reduced glucose excursions by $53 \%$.

Conclusion/interpretation. Nateglinide is more rapidacting and rapidly-reversible than is repaglinide. By restoring a more physiologic insulin profile, nateglinide is more effective than repaglinide in controlling prandial glucose excursions with less hyperinsulinaemia. [Diabetologia (2003) 46[Supp11]:M22-M29]

Keywords Early insulin secretion, prandial glucose excursions.
Received: 17 April 2001 / Revised: 5 September 2001

Published online: 9 November 2002

(C) Springer-Verlag 2002

This work was presented at the $35^{\text {th }}$ Annual Meeting of the EASD

Corresponding author: B. E. Dunning, Novartis Pharmaceuticals Corporation, 13550 A Drive North, Ceresco, MI 49033, USA, E-mail: BEDunning@aol.com

Abbreviations: PK, Pharmacokinetics; PD, pharmacodynamics; IRI, immunoreactive insulin; IRG, immunoreactive glucagon; HPLC-UV, high performance liquid chromatography with ultra violet detection; ACS-ACOD, acyl-CoA synthetase-acylCoA oxidase.
It has been shown convincingly that in Type 2 (noninsulin-dependent) diabetes mellitus [1,2] and even in precursors thereof [3] the kinetics of insulin secretion are disrupted despite the existence of absolute (if not relative) hyperinsulinaemia. The disrupted insulin secretory kinetics can be confirmed by either the absence of the acute insulin response to i.v. glucose [4] or a sluggish insulin response to oral glucose [5] or a meal [6]. The impaired early insulin response leads to a marked impairment of the suppression of endogenous glucose production normally seen after glucose administration or a meal $[5,6]$ and to a lesser extent, a later decrease of peripheral glucose utilization [6]. 
It is therefore not surprising that administration of a modest amount of insulin at the beginning of a meal (i.e., replacing the early insulin response by exogenous insulin, either iv administration of insulin per se or subcutaneous administration of a rapid-acting insulin analogue) is more effective than the same amount of, or even more insulin administered at a later time $[7,8]$. Furthermore, if an early increase of insulin were produced by stimulating endogenous insulin secretion, thus providing portal insulin delivery, optimal prandial glucose control could be achieved.

Recently two orally-effective insulinotropic agents, namely the D-phenylalanine derivative, nateglinide, and the benzoic acid derivative, repaglinide, have been claimed to stimulate insulin release rapidly and transiently [9]. However, when the pharmacodynamics of these two agents have been compared directly in the perfused rat pancreas [10] or in vivo in rodents [11] it was found that the effects of nateglinide are more rapidly manifest and shorter in duration than are the effects of repaglinide. As reviewed recently [12], marked differences in the kinetics of ligand/receptor interactions and closure of the $\mathrm{K}^{+}{ }_{\text {ATP }}$ channel seem to, at least in part, underlie the kinetic differences observed in vivo. However, to date such comparative studies have been limited to lower animal species and whether the metabolically-important pharmacodynamic differences would be reproduced in higher species has not been determined.

The purpose of this study was first to determine whether there are major pharmacokinetic or pharmacodynamic differences between nateglinide and repaglinide in non-human primates and if so, whether a faster onset and more rapidly-reversible insulinotropic effect would provide better prandial glucose control with less peripheral hyperinsulinaemia. These questions were explored using obese Cynomolgus monkeys that have each of the metabolic defects that characterize early Type 2 diabetes in humans [13].

\section{Materials and methods}

Animals and procedures. Studies were done with a group of 24 adult male herpes B virus-free Cynomolgus monkeys (macaca fascicularis). All protocols were approved by the institutional animal care and use committee, and animal husbandry and maintenance were in accordance with the National Institutes of Health Guide for the Care and Use of Laboratory Animals [14]. To model early human Type 2 diabetes, obesity and metabolic derangements had been induced in the subjects by provision of caloric excess in the form of ad libitum access to fruit-flavoured pellets of a high fat diet (51\% of calories from saturated fat, Bio-Serve, Frenchtown, N.J., USA) supplemented daily with standard monkey biscuits, fruit, fruit juice and a variety of highly palatable treats such as candy, cookies and buttered popcorn. Animals were housed individually in a temperature and humidity-controlled environment with a 12-h light to dark cycle and were provided with daily activities (such as television, movies, toys, human interaction etc.).
Two studies were carried out. The first study used 16 monkeys $(6.8$ to $10.2 \mathrm{~kg}$ ) and was done to compare the pharmacokinetics and pharmacodynamics of nateglinide and repaglinide. Six animals received $20 \mathrm{mg} / \mathrm{kg}$ of nateglinide orally in vehicle $(0.5 \%$ carboxymethylcellulose containing $0.2 \%$ Tween- 80 in a volume of $1.0 \mathrm{ml} / \mathrm{kg}$ ), six monkeys received $0.1 \mathrm{mg} / \mathrm{kg}$ repaglinide in vehicle and four monkeys received vehicle alone. Monkeys were fasted at $\sim 12: 30$ p.m. on the day before the study, immediately after receiving their daily fruit treat.

On the study day, animals received an initial dose of ketamine $(15 \mathrm{mg} / \mathrm{kg}$, i.m.) at approximately 7:00 a.m., followed after $20 \mathrm{~min}$ by diazepam (Valium, $1 \mathrm{mg} / \mathrm{kg}$, i.m.). Supplemental ketamine was given as an i.v. infusion at an initial rate of $0.25 \mathrm{mg} \cdot \mathrm{kg}^{-1} \cdot \mathrm{min}^{-1}\left(0.125 \mathrm{ml} \cdot \mathrm{kg}^{-1} \cdot \mathrm{min}^{-1}\right.$ of a solution containing $2 \mathrm{mg} / \mathrm{ml}$ ) and the infusion rate was adjusted to maintain a stable plane of anesthesia as assessed by monitoring blood pressure, heart rate, respiratory rate and muscular rigidity.

After the animals were anaesthetized, an appropriately sized trachea airway tube with inflatable cuff was inserted and secured with a gauze bandage tie. For blood sampling, an 8 -inch, 22-gauge catheter was placed in a saphenous vein and advanced to the iliac vein or possibly as far as the inferior vena cava. A short catheter was placed in the saphenous vein of the opposite leg for infusing saline to hydrate the animal during the experiment and to allow administration of supplemental ketamine.

A total of 21 blood samples $(2.5 \mathrm{ml})$ was collected during a 4-h experimental period. Five basal samples were collected $(-30,-20,-10,-5$ and $0 \mathrm{~min})$ then the test article was administered by oral gavage using a gastric tube inserted into the stomach. Additional blood samples were collected from monkeys $5,10,15,20,25,30,40,50,60,70,80,90,120,150,180$ and $210 \mathrm{~min}$ after compound administration. After the final sample was collected, aminopentamide (Centrine, $0.02 \mathrm{mg} / \mathrm{kg}$, i.m., Henry Schein, Ft. Washington, N.Y., USA) was administered to pre-empt vomiting, and the animals were returned to their home cage and given access to food and water and allowed to recover full consciousness.

The second study was done to compare the influence of nateglinide and repaglinide on prandial glucose excursions and insulin concentrations. This protocol used a total of 21 monkeys $(6.1$ to $11.0 \mathrm{~kg})$ that were anaesthetized, instrumented and handled as described above. Seven monkeys received $20 \mathrm{mg} / \mathrm{kg}$ of nateglinide orally in vehicle, eight monkeys received $0.1 \mathrm{mg} / \mathrm{kg}$ repaglinide in vehicle and six monkeys received vehicle alone. A total of 18 blood samples $(2.5 \mathrm{ml})$ were collected during a 4-h experimental period. Three basal (pre-dose) samples were collected $(-20,-15,-10 \mathrm{~min})$ then the test article was administered by oral gavage. Two post-dose, pre-meal blood samples were collected $(-5$ and 0 min after compound administration) then a liquid mixed meal supplemented with glucose (Sustacal, $3 \mathrm{ml} / \mathrm{kg}$ containing $0.5 \mathrm{gm} / \mathrm{kg}$ dextrose) was administered by gavage as described above. Additional blood samples were taken at 2, 5, 10, 15, 20, 30, $45,60,90,120,150,180$ and 210 after the meal.

Sample handling and analysis. All samples were collected into 3-cc syringes and divided as follows: $2.0 \mathrm{ml}$ were transferred into a heparanized vacutainer tube, centrifuged, and plasma was aliquoted for insulin, glucose and lactate determinations and for subsequent analyses of drug concentrations; $0.5 \mathrm{ml}$ were transferred into $1.5 \mathrm{ml}$ microcentrifuge tubes containing $10 \%$ EDTA/trasysol for measuring glucagon and NEFA.

Plasma glucose was measured by the glucose oxidase technique using an automated analyser (YSI 2700, Yellow Springs Instrument, Yellow Springs, Ohio, USA) and insulin was measured with a non-radioactive competitive enzymatic assay on an automated analyser (IMX, Abbott Diagnostics, Abbott Park, 
Ill., USA). Plasma concentrations of NEFA were measured by the ACS-ACOD method using a kit (Wako Chemicals, Neuss, Germany) with the prescribed procedure modified to reduce sample volume. Plasma concentrations of immunoreactive glucagon (IRG) were measured by radioimmunoassay using a kit (Linco, St. Louis, Mo., USA). After solid phase or liquidliquid extraction of plasma samples, respectively, nateglinide and repaglinide concentrations were determined using HPLCUV.

Data are reported as means \pm SEM. Baseline (used interchangeably with "basal") values were calculated as the mean of the $-20,-15$ and -10 min samples. Pre-meal and post-dose concentrations were calculated as the mean of the -5 and 0 min samples. Incremental areas above (or below) baseline were calculated by the trapezoidal method. Time course data were analysed by repeated measures of ANOVA. Statistical differences between the two groups were determined by unpaired Student's $t$ test. Differences from baseline to a specific time point within a group were assessed with a paired $t$ test. When the direction of the difference was predicted (e.g., when determining if the compound stimulated insulin release) a one-tailed test was done, when the null hypothesis was that the groups were not different, a two-tailed test was carried out.

\section{Results}

Pharmacokinetics and pharmacodynamics. There was no measurable nateglinide or repaglinide in the vehicle-treated monkeys or in the active treatment groups before the compound was administered. The mean nateglinide or repaglinide concentrations occurring after oral administration of the compounds are shown (Fig. 1). Absorption of nateglinide was very rapid and appeared to be biphasic in the anaesthetized monkey. Mean peak nateglinide concentrations $(\sim 56 \mu \mathrm{mol} / \mathrm{l})$ occurred on average at $30 \mathrm{~min}$ post-dose (ranging from 15 to $50 \mathrm{~min}$ ) and a second smaller peak averaged $42 \mu \mathrm{mol} / \mathrm{l}$ and occurred at $90 \mathrm{~min}$ (ranging from 70 to $150 \mathrm{~min}$ ). Mean peak repaglinide concentrations $(\sim 81 \mathrm{nmol} / \mathrm{l})$ occurred on average at $50 \mathrm{~min}$ post-dose and ranged from 25 to $150 \mathrm{~min}$. There was evidence of a second phase of absorption in four of six repaglinide-treated monkeys. However, plasma concentrations of repaglinide even at peak concentrations was nearing the detection limit of the assay. Thus a second phase of absorption might have occurred in each animal.

Basal (mean of $-10,-5$ and 0 min samples) plasma concentrations of immunoreactive insulin (IRI) averaged $82 \pm 14,178 \pm 104$ and $81 \pm 15 \mathrm{pmol} / \mathrm{l}$ in the monkeys randomly assigned to receive nateglinide, repaglinide and vehicle, respectively. After administration of nateglinide $(20 \mathrm{mg} / \mathrm{kg})$ IRI concentrations increased rapidly, reaching a peak at $25 \mathrm{~min}$ which was $402 \pm 136 \mathrm{pmol} / \mathrm{l}$ above baseline but returned to basal concentrations within $60 \mathrm{~min}$ (Fig. 2A). Plasma IRI increased more slowly after administration of repaglinide $(0.1 \mathrm{mg} / \mathrm{kg})$ : a peak which was $449 \pm$ $328 \mathrm{pmol} / \mathrm{l}$ above baseline occurred $70 \mathrm{~min}$ post-dose and IRI concentrations remained above baseline $3.5 \mathrm{~h}$

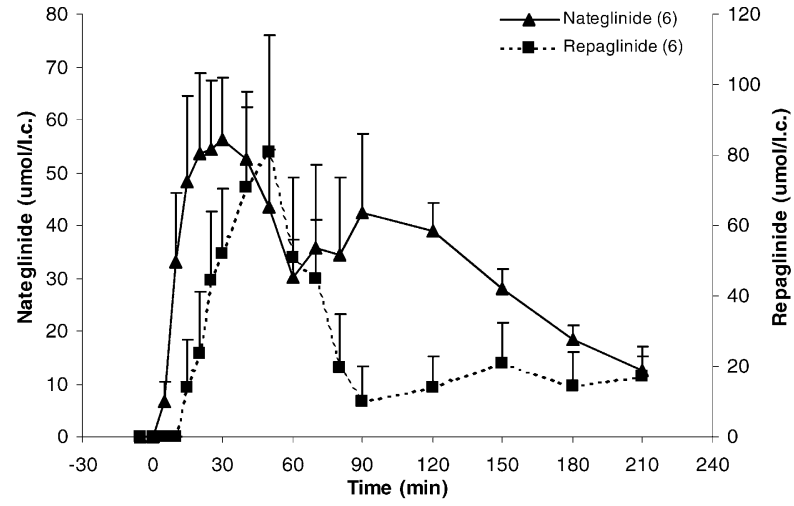

Fig. 1. Plasma drug concentrations after oral administration of nateglinide or repaglinide in overnight-fasted pre-diabetic Cynomolgus monkeys. Means $\pm \mathrm{SEM}, n=6$ monkeys per group
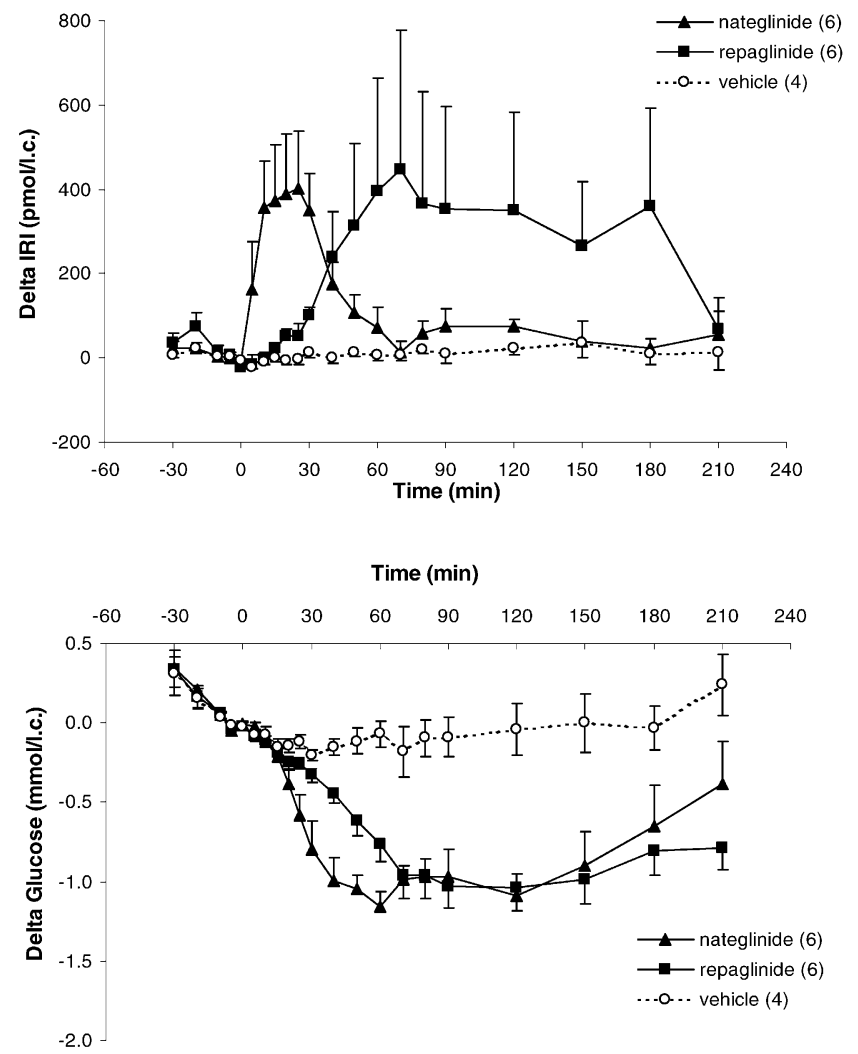

Fig. 2A, B. Change of plasma immunoreactive insulin (IRI, A) and glucose (B) after oral administration of nateglinide $(20 \mathrm{mg} / \mathrm{kg})$, repaglinide $(0.1 \mathrm{mg} / \mathrm{kg})$ or vehicle $(1 \mathrm{ml} / \mathrm{kg})$ in overnight-fasted pre-diabetic Cynomolgus monkeys. Means \pm SEM

post-dose. Insulin concentrations did not change after vehicle administration.

Basal plasma glucose concentrations averaged $2.8 \pm 0.1,2.9 \pm 0.1$ and $3.0 \pm 0.2 \mathrm{mmol} / 1$ in the groups destined to receive nateglinide, repaglinide and vehicle, respectively. Plasma glucose concentrations decreased in response to nateglinide and to repaglinide but remained stable after administration of vehicle alone (Fig. 2B). The hypoglycaemic response to nate- 
glinide was more rapid and less sustained than the response to repaglinide. After nateglinide was administered the first substantial decrease of plasma glucose concentrations $(-0.4 \pm 0.1 \mathrm{mmol} / \mathrm{l})$ occurred within $20 \mathrm{~min}$. A nadir that was $1.2 \pm 0.1 \mathrm{mmol} / \mathrm{l}$ below baseline occurred $60 \mathrm{~min}$ post-dose and glucose concentrations increased thereafter, returning to baseline within $3 \mathrm{~h}$. The first substantial decrease of glucose $(-0.3 \pm 0.1 \mathrm{mmol} / \mathrm{l})$ occurred $30 \mathrm{~min}$ after repaglinide was administered. A nadir that was $1.4 \pm 0.2 \mathrm{mmol} / 1$ below baseline occurred $120 \mathrm{~min}$ post-dose and glucose remained significantly below baseline $(-0.8 \pm$ $0.2 \mathrm{mmol} / \mathrm{l}$ ) for the entire 3.5 -h post-dose sampling period. Plasma glucose concentrations did not change after vehicle administration.

Figure 3 depicts the primary pharmacodynamic (PD) parameter (insulin) together with the pharmacokinetic $(\mathrm{PK})$ profile in monkeys that received nateglinide or repaglinide to compare the PK/PD relationships between the two compounds. After administration of nateglinide insulin concentrations increased immediately when the compound in the circulation appeared. Plasma IRI peaked before maximal nateglinide concentrations were achieved and returned to baseline before the compound was cleared. After administration of repaglinide the increase of insulin lagged behind the appearance of the compound in circulation and insulin concentrations remained increased for $2 \mathrm{~h}$ after clearance of the compound.

Basal concentrations of immunoreactive glucagon (IRG) in the monkeys which were to receive nateglinide, repaglinide and vehicle averaged $86 \pm 11,97 \pm 20$ and $77 \pm 14 \mathrm{ng} / \mathrm{l}$, respectively. Glucagon concentrations were initially suppressed after treatment with nateglinide $(-11 \pm 4 \mathrm{ng} / \mathrm{l}$ at $15 \mathrm{~min})$ then rose gradually thereafter. After administration of repaglinide, IRG did not decrease; rather IRG concentrations steadily increased throughout the post-dose sampling period. Glucagon concentrations also increased gradually after vehicle administration. While the absolute concentrations of IRG were higher and the changes from baseline were greater for the final $2 \mathrm{~h}$ of sampling in the animals receiving repaglinide than in the other two groups, these differences did not achieve statistical significance.

Baseline NEFA concentrations averaged $0.68 \pm 0.05$, $0.62 \pm 0.12$ and $0.66 \pm 0.08 \mathrm{mEq} / \mathrm{l}$ in the monkeys which were to receive nateglinide, repaglinide and vehicle, respectively. NEFA concentrations tended to decrease modestly in the compound-treated animals but these changes did not achieve statistical significance. NEFA concentrations tended to increase (also not significantly) after administration of vehicle.

Heart rate, respiratory rate and arterial blood pressure were monitored in all animals during the course of the experiments. These parameters did not differ among groups and did not change significantly after administration of compound or vehicle.
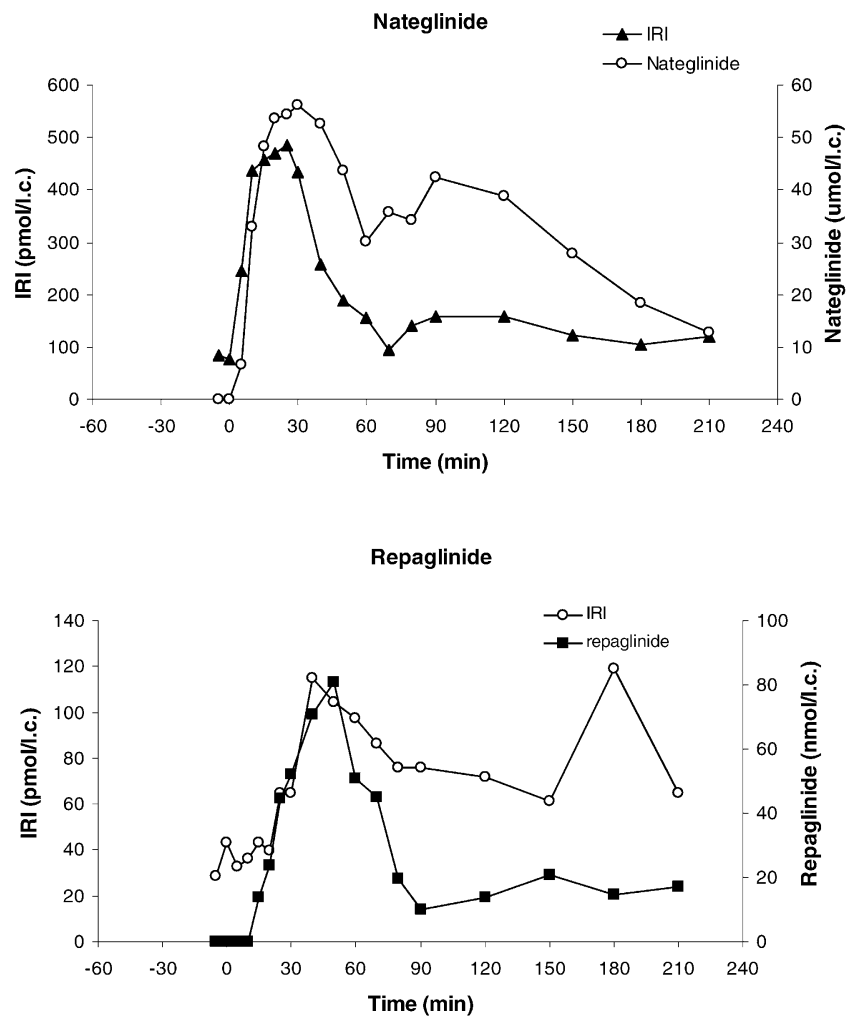

Fig. 3A, B. Mean plasma concentrations of nateglinide (A) or repaglinide (B) and immunoreactive insulin (IRI) after oral administration of compounds in overnight-fasted pre-diabetic Cynomolgus monkeys. $n=6$ monkeys per group, standard error bars omitted for clarity

Meal tolerance tests. Basal plasma IRI concentrations averaged $72 \pm 6,192 \pm 84$ and $120 \pm 30 \mathrm{pmol} / \mathrm{l}$ in monkeys destined to receive nateglinide, repaglinide and vehicle, respectively. The difference between groups receiving the two compounds is not statistically significant and largely reflects one very hyperinsulinaemic monkey in the group to receive repaglinide. The difference in basal IRI between nateglinide and vehicle groups was significant $(p<0.05)$ but not likely to be metabolically-important.

As shown in the inset of Fig. 4A, plasma IRI concentrations remained relatively constant after administration of vehicle or repaglinide and did not begin to increase until 5 min after administration of the liquid meal. In contrast, IRI concentrations increased rapidly and substantially after administration of nateglinide ( $\Delta$ at time $0=+210 \pm 54 \mathrm{pmol} / 1, p<0.005$ vs pre-dose). The change of plasma IRI concentrations during the full 4-h experimental period is shown (Fig. 4A). The plasma IRI concentrations were similar in the vehicletreated and nateglinide-treated groups throughout the post-meal period, reaching peak increases at $20 \mathrm{~min}$ which were $1254 \pm 648$ and $948 \pm 462 \mathrm{pmol} / 1$, respectively. Plasma IRI concentrations were higher and more sustained in the animals that received repaglinide, reaching a peak of $2256 \pm 516 \mathrm{pmol} / 1$ at $30 \mathrm{~min}$ after the meal. However, owing to the variability men- 

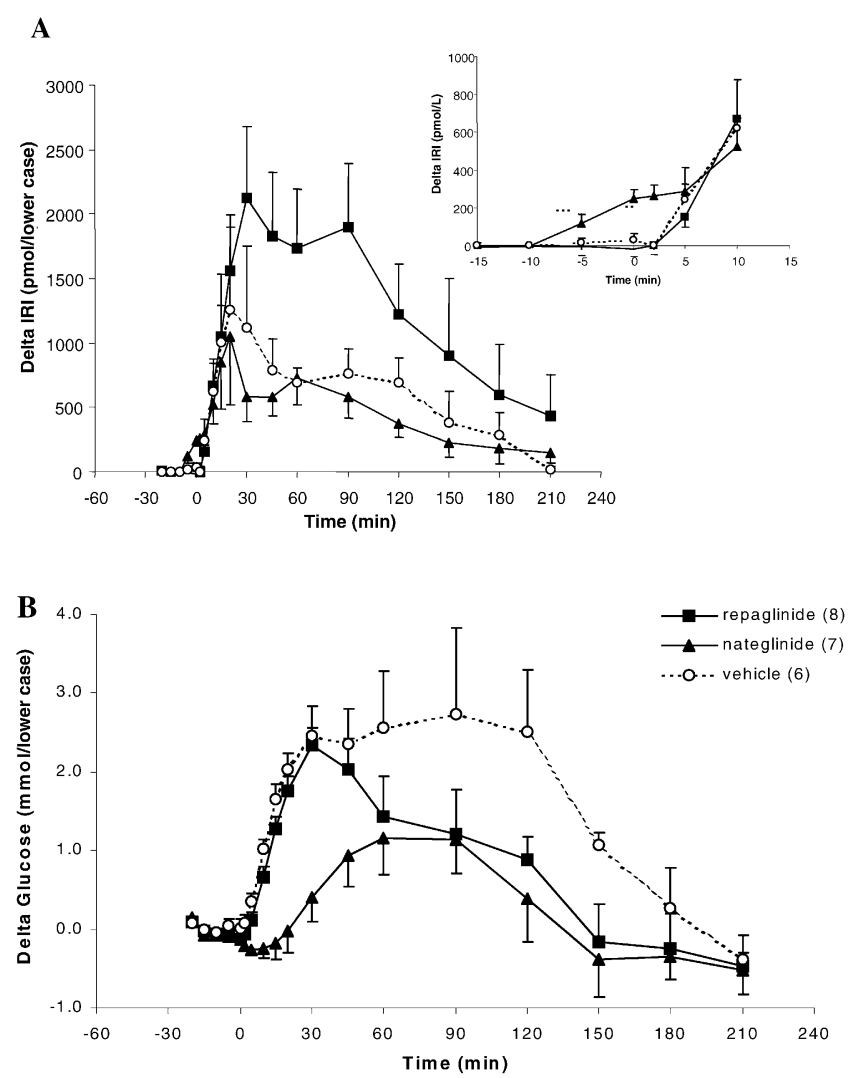

Fig. 4A, B. Change of plasma concentrations of immunoreactive insulin (IRI, A) and glucose (B) after oral administration of nateglinide $(20 \mathrm{mg} / \mathrm{kg})$, repaglinide $(0.1 \mathrm{mg} / \mathrm{kg})$ or vehicle (at time -10) followed by a glucose-supplemented liquid meal at time zero (Sustacal, $3 \mathrm{ml} / \mathrm{kg}$ supplemented to contain $0.5 \mathrm{gm} / \mathrm{kg}$ glucose $)$. Means \pm SEM

tioned above, many of the differences at individual time points did not achieve statistical significance.

Basal (pre-dose) plasma glucose concentrations averaged $2.9 \pm 0.1,2.9 \pm 0.1$ and $3.2 \pm 0.1 \mathrm{mmol} / \mathrm{l}$ in monkeys randomly assigned to receive nateglinide, repaglinide and vehicle, respectively. Figure 4B illustrates the change of plasma glucose relative to the individual basal values after administration of compound and then the meal. In the vehicle-treated control animals, plasma glucose concentrations increased after the meal, reaching a peak at 30 min which averaged $2.4 \pm 0.5 \mathrm{mmol} / \mathrm{l}$ above baseline (pre-dose) concentrations. The initial $45 \mathrm{~min}$ of the prandial glucose profile in monkeys which received repaglinide was superimposable on that observed in the control animals. In repaglinide-treated monkeys, plasma glucose reached a peak at $30 \mathrm{~min}$ that averaged $2.3 \pm 0.2 \mathrm{mmol} / \mathrm{l}$ above pre-dose concentrations. Thereafter glucose concentrations decreased more rapidly in the repaglinide-treated group, being lower than control (vehicle-treated) concentrations at 120 and $150 \mathrm{~min}$ post-meal. In the group that received nateglinide, glucose excursions were delayed and diminished relative to the vehicle-treated and to the repaglinide-treated groups. The maximum of the average
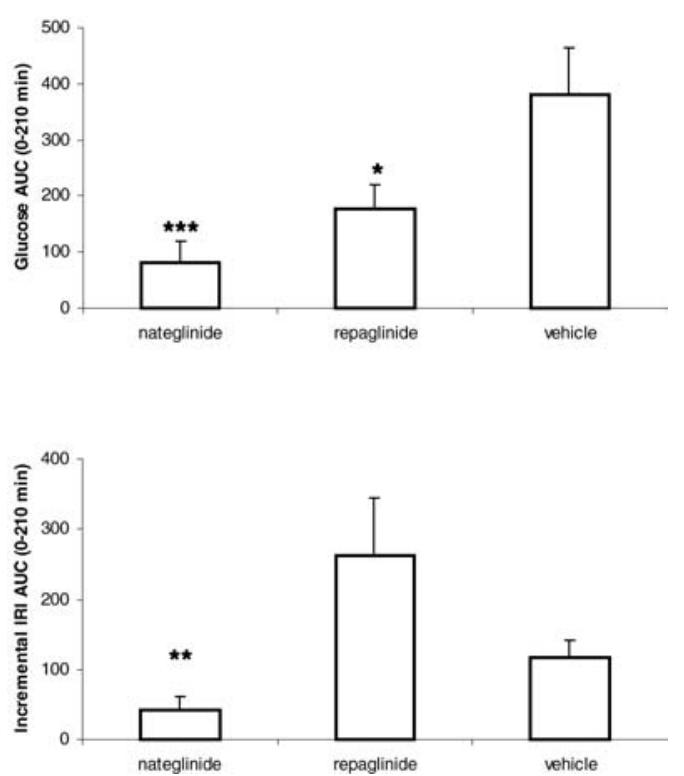

Fig. 5A, B. Incremental areas under the curve (AUC) from time 0 to $210 \mathrm{~min}$ for glucose (A) and immunoreactive insulin (IRI, B) after oral administration of a liquid meal (Sustacal, $3 \mathrm{ml} / \mathrm{kg}$ supplemented to contain $0.5 \mathrm{gm} / \mathrm{kg}$ glucose) in prediabetic monkeys that had received nateglinide $(20 \mathrm{mg} / \mathrm{kg}$, $n=7)$, repaglinide $(0.1 \mathrm{mg} / \mathrm{kg}, n=8)$ or vehicle $(1 \mathrm{ml} / \mathrm{kg}, n=6)$ at time -10 min relative to the meal. Means \pm SEM. ${ }^{*} p<0.05$ vs vehicle, ${ }^{* *} p<0.05$ vs repaglinide or vehicle, ${ }^{* * *} p<0.005$ vs vehicle

glucose concentration occurred at 60 min post-meal in monkeys which received nateglinide, and this value was $1.3 \pm 0.4 \mathrm{mmol} / \mathrm{l}$ above basal values.

The meal-induced incremental areas under the curve for insulin and glucose were calculated (Fig. 5). The AUC for glucose was reduced by $79 \%$ and $53 \%$ in monkeys that received nateglinide and repaglinide, respectively, relative to vehicle treated control monkeys. The incremental insulin $\mathrm{AUC}_{0-210}$ min was approximately twofold higher and 50\% lower than that in the control monkeys that received nateglinide and repaglinide, respectively.

Basal plasma concentrations of IRG averaged $85 \pm 10,97 \pm 19$ and $62 \pm 7 \mathrm{ng} / \mathrm{l}$ in the animals which were to receive nateglinide, repaglinide and vehicle, respectively. Plasma IRG concentrations were suppressed below baseline from 15 to 150 min post-meal and rose above basal concentrations thereafter in each group of animals. Baseline NEFA concentrations averaged $0.58 \pm 0.04,0.66 \pm 0.06$ and $0.74 \pm 0.09 \mathrm{mEq} / 1$ in the monkeys which were to receive nateglinide, repaglinide and vehicle, respectively. NEFA concentrations decreased substantially and similarly after administration of the liquid meal in each group of animals.

Heart rate, respiratory rate and arterial blood pressure were monitored in all animals during the course of the experimental period. These parameters did not differ among groups and did not change after adminis- 
tration of compound or vehicle with two minor exceptions. The initial mean arterial blood pressure was marginally lower in the animals which were to receive nateglinide than in those to receive vehicle and heart rate in each group tended to decrease modestly and gradually over the course of the experimental period.

\section{Discussion}

The purpose of this work was first to compare the pharmacodynamics and pharmacokinetics of two reportedly rapid-onset, rapidly-reversible insulinotropic agents, nateglinide and repaglinide, and second, to assess the effect of augmenting early insulin secretion on prandial glucose control. The studies used male Cynomolgus monkeys that had been maintained on a high fat, high simple carbohydrate diet to induce obesity and insulin resistance. These monkeys have been shown to have each of the metabolic defects that characterize early Type 2 diabetes in humans. In comparison to measures done while they were on a standard chow diet, these animals were insulin-resistant and hyperinsulinaemic, with impaired early insulin release, increased NEFA and modestly increased fasting glucose concentrations [13]. Accordingly, the subjects could be considered pre-diabetic and a good animal model of early diabetes in humans.

In the interest of animal and human safety, studies were carried out while monkeys were sedated and chemically restrained by variable rate infusion of ketamine. Ketamine-induced sedation has been shown to modestly suppress plasma glucose and insulin concentrations in baboons [15] possibly accounting for the relatively low fasting plasma glucose concentrations observed in this study. However, a stable and consistent plane of anesthesia is achievable by the protocol used [16] and any differences between groups treated with different agents should be attributable to the compounds per se. The doses of compound used were chosen based on preliminary range-finding studies which indicated that $20 \mathrm{mg} / \mathrm{kg}$ of nateglinide would elicit an increment of plasma IRI equivalent to that induced by $0.1 \mathrm{mg} / \mathrm{kg}$ of repaglinide.

The main findings of the PK and PD study were that, as seen in normal rodents [11], the onset of the insulinotropic action of nateglinide was more rapid than that of repaglinide and the duration of stimulation of insulin release induced by nateglinide was much shorter than that induced by repaglinide. As a consequence, glucose concentrations decreased more rapidly in response to nateglinide than in response to repaglinide and recovered to baseline values in animals which received nateglinide more promptly than in animals which received repaglinide. Thus in a non-human primate model of early diabetes, nateglinide is appropriately described as a rapidly-reversible insulinotropic agent with a low potential to produce severe or sustained hypoglycaemia.
The differential pharmacodynamics of nateglinide and repaglinide could reflect both mechanistic differences, as described in electrophysiologic [17] and secretion studies in vitro [10] and pharmacokinetic differences. Consistent with findings in humans [18] nateglinide was absorbed very rapidly and the insulin concentrations "tracked" the drug concentrations very well. A second phase of absorption is also occasionally seen in humans [18] and is possibly exaggerated in our studies because the monkeys were sedated and in a recumbent position. Repaglinide seemed to be absorbed more slowly than nateglinide but eliminated more rapidly.

Of note, comparing the PK and PD relationships of nateglinide and repaglinide suggests a new glucose dependence of the insulinotropic effects of nateglinide that has also been observed in mechanistic studies [19]. It was apparent that after nateglinide administration insulin concentrations returned to baseline during the development of hypoglycaemia despite continued presence of high plasma concentrations of nateglinide. In contrast, after administration of repaglinide, high insulin concentrations were maintained despite ongoing hypoglycaemia and clearance of the compound from the circulation. Such glucose dependence of nateglinide action could be predicted to further increase the safety margin relative to hypoglycaemic episodes.

There was no evidence of a direct action of either agent on glucagon secretion in these studies and neither agent affected circulating NEFA. It may be surprising that NEFA concentrations were not influenced by treatment with either compound despite substantial increases of circulating insulin. This could in part reflect the insulin-resistant state of the subjects but it is also possible that the lipolytic rate was low in these animals due to a neurosuppressive effect of the sedative used, thus further insulin-mediated suppression of lipolysis would be difficult to detect. Nevertheless, since the animals were in the fasted state, this finding does indicate that the insulin-mediated glucose lowering observed after treatment with either agent represents a direct effect of insulin to suppress hepatic glucose production and/or to increase peripheral glucose uptake [20] rather than an indirect effect mediated by lowering NEFA [21].

The major findings from the meal tolerance tests were that, as seen in normal rodents [11], nateglinide, but not repaglinide exerted a preferential effect on early insulin release and as a result, nateglinide blunted the glucose excursion induced by a glucosesupplemented liquid meal more completely than did repaglinide. In addition, incremental insulin response to the meal was not only smaller in monkeys treated with nateglinide than in those which received repaglinide, but incremental insulin response was less than half of that in the vehicle-treated control animals due to the reduced glucose stimulus for continued insulin release. 
That the increment of IRI concentrations in response to nateglinide occurred before the meal (meal given 10 min post-dose) is not surprising and is entirely consistent with the PK and PD study discussed above. What is perhaps remarkable is that this modest pre-meal insulin release, mimicking the "cephalic phase" [22] exerted such a profound effect on both prandial glucose excursions and the subsequent mealstimulated insulin release. It has been shown clearly in patients with Type 2 diabetes that reproducing the increment of portal IRI concentrations that occurs in normal subjects early during the course of a meal does blunt glucose excursions and reduce insulin concentrations later on [23]. Our findings could provide further evidence that cephalic insulin release plays a critical role in nutrient handling and that early insulin release can greatly reduce glucose excursions and limit the insulin necessary to dispose of the excursion if it occurs.

The mechanism by which a small increase of insulin before or at the beginning of a meal profoundly curtails mealtime glucose excursions was not investigated in this study. Available evidence, however, suggests that it is likely due to a direct effect of insulin to switch the liver from a state of production to one of uptake and storage [20]. Such a direct effect is also supported by the observation that NEFA (potential mediator of insulin-induced reduction of hepatic glucose output) were suppressed similarly in the control and nateglinide-treated and repaglinide-treated groups. The finding that NEFA were not suppressed to a greater degree in the group which received repaglinide, despite a substantially greater increase of IRI probably reflects the fact that postmeal NEFA concentrations were very low in all animals.

In summary, the results show that in non-human primates the insulinotropic and glucose-lowering effects of nateglinide are more rapidly manifest and shorter in duration than those of repaglinide. Comparison of the PK and PD profiles of the two compounds suggests that the differential pharmacodynamics largely reflect inherent mechanistic differences including a novel glucose-dependent character of the insulinotropic effect of nateglinide. Furthermore, when given before a meal, nateglinide exerts a preferential effect on early insulin release and profoundly limits prandial glucose excursions. In contrast, repaglinide increases insulin concentrations during and for more than $3.5 \mathrm{~h}$ after a meal compared to vehicletreated animals yet repaglinide controls prandial glucose excursions less effectively than does nateglinide. These findings predict potentially important therapeutic advantages of nateglinide for the treatment of Type 2 diabetes mellitus; namely, that it can provide better meal-time glucose control with less hyperinsulinaemia and hypoglycaemic potential than other insulinotropic agents.

\section{References}

1. Seltzer HS, Allen EW, Herron AL, Jr, Brennen MT (1967) Insulin secretion in response to glycemic stimulus: relation of delayed initial release to carbohydrate intolerance in mild diabetes. J Clin Invest 46: 323-335

2. Polonsky KS, Given BD, Hirsch LJ et al. (1988) Abnormal patterns of insulin secretion in non-insulin-dependent diabetes mellitus. N Engl J Med 318: 1231-1239

3. Weyer C, Bogardus C, Mott DM, Pratley RE (1999) The natural history of insulin secretory dysfunction and insulin resistance in the pathogenesis of type 2 diabetes mellitus. J Clin Invest 104: 787-794

4. Brunzell JD, Robertson RP, Lerner RL et al. (1976) Relationships between fasting plasma glucose levels and insulin secretion during intravenous glucose tolerance tests. J Clin Endocrinol Metab 42: 222-229

5. Mitrakou A, Kelley D, Mokan M et al. (1992) Role of reduced suppression of glucose production and diminished early insulin release in impaired glucose tolerance. $\mathrm{N}$ Engl J Med 326: 22-29

6. Kelley D, Mokan M, Veneman T (1994) Impaired postprandial glucose utilization in non-insulin-dependent diabetes mellitus. Metabolism 43: 1549-1557

7. Bruttomesso D, Pianta A, Mari A et al. (1999) Restoration of early rise in plasma insulin levels improves the glucose tolerance of type 2 diabetic patients. Diabetes 48: 99-105

8. Dimitriadis GD, Gerich JE (1983) Importance of timing of preprandial subcutaneous insulin administration in the management of diabetes mellitus. Diabetes Care 6: 374377

9. Kikuchi M (1996) Modulation of insulin secretion in non-insulin-dependent diabetes mellitus by two novel oral hypoglycaemic agents, NN623 and A4166. Diabet Med 13: S151-S155

10. Leclercq-Meyer V, Ladriere L, Fuhlendorff J, Malaisse WJ (1997) Stimulation of insulin and somatostatin release by two meglitinide analogs. Endocrine 7: 311-317

11. de Souza CJ, Russo P, Lozito R, Dunning BE (2000) Differential effects of short and long duration insulinotropic agents on meal related glucose excursions. Diabetes Obes Metab 3: 73-83

12. Pratley RE, Foley JE, Dunning BE (2001) Rapid acting insulinotropic agents: restoration of early insulin secretion as a physiologic approach to improve glucose control. Curr Pharm Des 7: 1375-1397

13. Dunning BE, Burkey BF, Dong M et al. (2000) Prolonged caloric excess in Cynomolgus monkeys produces a nonhuman primate model of early type 2 diabetes. Diabetes 49 [Suppl 1]: A312 (Abstract 1303-P)

14. Institute of Laboratory Animal Resources CoLSNRC (1996) Guide for the care and use of laboratory animals. National Academy Press, Washington

15. Lehmann R, Wagner JL, Fernandez LA et al. (1997) Effects of ketamine sedation on glucose clearance, insulin secretion and counterregulatory hormon production in baboons (Papio hamadryas). J Med Primatol 26: 312321

16. Castro MI, Rose J, Green W, Lehner N, Peterson D, Taub D (1981) Ketamine-HCl as a suitable anesthetic for endocrine, metabolic, and cardiovascular studies in Macaca fascicularis monkeys. Proc Soc Exp Biol Med 168: 389-394

17. Hu S, Wang S, Fanelli B et al. (2000) Pancreatic $\beta$-cell KATP channel activity and membrane binding studies with nateglinide: a comparison with sulfonylureas and repaglinide. J Pharm Exp Ther 293: 444-452 
18. Tse FLS, Labbadia D, Habucky K, Karara A, Au S (1996) Effect of food on the bioavailability of SDZ DJN 608, an oral hypoglycemic agent, from a tablet and a liquid-filled capsule in the dog. Pharm Res 13: 440-444

19. Hu S, Wang S (2001) Glucose-dependent and glucose-sensitizing insulinotropic effects of nateglinide: comparison to glyburide and repaglinide. Int J Exp Diabet Res 2: 63-72

20. Sindelar DK, Chu CA, Venson P, Donahue EP, Neal DW, Cherrington AD (1998) Basal hepatic glucose production is regulated by the portal vein insulin concentration. Diabetes 47: $523-529$
21. Ader M, Bergman RN (1990) Peripheral effects of insulin dominate suppression of fasting hepatic glucose production. Am J Physiol 258: E1020-E1032

22. Teff KL, Mattes RD, Engelman K, Mattern J (1993) Cephalic-phase insulin in obese and normal-weight men: relation to postprandial insulin. Metabolism 42: 16001608

23. Bruce DG, Chisholmn DJ, Storlien LH, Kraegen EW (1988) Physiological importance of deficiency in early prandial insulin secretion in non-insulin-dependent diabetes. Diabetes 37: 736-744 